\title{
Different Genes for Different Folks in Tree Crops: What Works and What Does Not
}

\author{
A.M. Dandekar, H.J. Fisk, G.H. McGranahan, S.L. Uratsu, H. Bains, C.A. Leslie, M. Tamura, M. Escobar, \\ J. Labavitch, C. Grieve, and T. Gradziel \\ Department of Pomology, One Shields Avenue, University of California Davis, Davis, CA 95616 \\ P.V. Vail and S.J. Tebbets \\ Horticulture Research Crops Laboratory, 2021 South Peach Avenue, Fresno, CA 93727
}

H. Sassa
Kihara Institute for Biological Research, Yokohama City University, Yokohama 244-0813, Japan
R. Tao
Graduate School of Agriculture, Kyoto University, Kyoto 606-8502, Japan

W. Viss and J. Driver

Dry Creek Laboratories, 1618 Baldwin Road, Hughson, CA 95326

D. James and A. Passey

Horticulture Research International, East Malling, West Malling, Kent ME19 6BJ, UK

G. Teo

\begin{abstract}
Dipartimento Di Agronomia Ambientale e Produzioni Vegetali, University of Padova Agripolis, via Romea 16, 35020 Legnaro (PD), Italy
\end{abstract}

Additional index words. disease, pest, and herbicide resistance; fruit and nut trees/quality; transgenic plants

\begin{abstract}
Whereas disease, pest and herbicide resistance have served as valuable entry points for plant biotechnology in general, the emphasis with crop plants is clearly shifting towards modifying traits that enhance quality, nutritional content and productivity. In tree crops this would involve specifically perturbing the expression patterns of endogenous genes associated with the trait under investigation. New tools such as enhanced gene silencing technology, EST database development, and total genome sequencing will likely accelerate the potential impact of this kind of work. Established plant transformation methods will continue to play crucial roles in evaluating newly discovered endogenous genes and in characterizing their function in whole plants. Examples of some of the areas in which we are currently integrating these kinds of approaches include the manipulation of sugar and ethylene metabolism in apples (Malus $\times$ domestica Borkh.), of oil/fat composition in walnut (Juglans regia L.) and of growth architecture in citrus. In almonds [Prunus dulcis (Mill.) D.A. Webb] we are studying self-incompatibility, a trait with potentially significant implications regarding productivity.
\end{abstract}

\section{GENES AS ALTERNATIVES TO CHEMICALS}

A major motivation to understand the genetic basis of disease and pest resistance in plants is to come up with alternatives to the use of chemicals that are incompatible with the environment. Agrichemicals such as pesticides, fungicides, or nematacides were a predominant feature of 20th century agriculture. As we enter the new millennium, the spirited search to discover genes that may serve as adequate substitutes for such compounds continues to expand. There are many options available and the list is growing. However, each candidate transgene must be tested for efficacy towards individual disease and pest problems on a crop-by-crop basis.

Engineering resistance to insect pests. Multiple approaches to confer resistance to insects have been tested in transgenic plants (Escobar and Dandekar, 2000). The most common strategies aimed to disrupt the digestive system of targeted insect pests. Of these, the most predominant involved the expression of the insecticidal crystal proteins (ICPs) of Bacillus thuringiensis (Bt), a common soil microorganism. Different strains of Bacillus thuringiensis collectively produce a

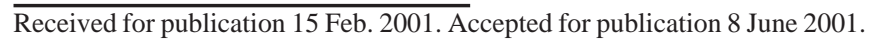

large family of distinct ICPs that are active against selective insect orders (Schnepf et al., 1998).

Our experimental emphasis has focused on genes encoding Lepidopteran-specific ICPs that target codling moth (CM; Cydia pomonella L.), navel orangeworm (NOW; Amyelois transitella Walker), oriental fruit moth (OFM; Grapholita molesta Bursh), and peach twig borer (Anarsia lineatella Zeller), significant pests in the apple, walnut, almond, and persimmon (Diospyros kaki L.) industries. Early work demonstrated significant mortality of $\mathrm{CM}$ and NOW to purified preparations of CryIAc and CryIAb proteins (Vail et al., 1991). However, no significant mortality was observed in transgenic apple and walnut plants that contained wild type cryIAc or cryIAb gene sequences (Dandekar et al., 1992, 1994). A major problem was the complete lack of expression of the wild-type gene sequences (Dandekar et al., 1994). Expression problems were due to various features of the wild-type gene sequences that included high AT content (codon usage), cryptic mRNA splice sites, and motifs that cause mRNA instability (Dandekar et al., 1994; Escobar and Dandekar, 2000). A strategy to circumvent these problems was reported by Perlak et al. (1991)and involved making alterations to the wild-type ICP through chemical synthesis. The restructured gene sequence eliminated the problems while retaining the original amino acid sequence. These restructured genes functioned very well in plants, allowing levels of expression $>500$-fold higher than those achieved using the coding region from the bacteria (Perlak et al., 1991). Using synthetic ICP genes, we have achieved high levels of mortality in codling moth from transgenic apple and walnut, in navel orangeworm from walnut and in oriental fruit moth from persimmon (Dandekar et al., 1992, 1998; Tao et al., 1997a). Currently we have two field trials underway in two different locations to test the field efficacy of transgenic walnuts expressing cryIAc genes under the control of two different regulatory sequences (CaMV35S and Ubi3). Similar work is under way with transgenic apple and plants are being targeted for commercialization.

Disease resistance. Obtaining viral resistance has been accomplished using genes isolated from the disease-causing viral genome. Genes under investigation have included those that encode coat or movement proteins and replicase. The expression of viral coat protein mediated resistance has been commercialized in squashes (Cucurbita sp.), melons (Cucumis sp.), and papaya (Carica papaya L.). In many instances the resistance is durable and appears to be RNA mediated via 
gene silencing (Baulcombe, 1999). As more is understood about the mechanism of gene silencing in plants, this approach may be used more widely to engineer resistance to many kinds of viral diseases.

Resistance against fungal and bacterial pathogens has been more difficult to achieve. There are two general approaches that are being actively investigated: 1) identification of natural resistance genes (master control switches for the plant defense response) and 2) expression of artificial resistance genes (genes that interfere with establishment, growth or reproduction of fungal/bacterial pathogens). The inducible defense response in plants that includes both localized (Lamb et al., 1989) and systemic response (Ryals and Ward, 1994) regulated by natural resistance genes involves expression of a number of genes that can block invasion, proliferation, and reproduction of pathogens. However, the natural resistance genes that regulate these mechanisms are very specific for a particular pathogen via a gene-forgene interaction. As more is understood of the structure and specificity of action of natural plant resistance genes, it may then be possible to engineer resistance to specific pathogens in crop plants. Additionally, genome sequencing projects will reveal disease resistance genes in crops of interest that in turn could be evaluated in transgenic plants. As for artificial resistance genes, a number of sequences have been identified as encoding products that confer disease resistance. Expression of these genes in plants has proved to be less effective against target fungal and bacterial pathogens. A broad spectrum approach to pathogens with a single gene like that described for the ICP of Btagainst insects is currently unavailable.

We have constructed many vectors containing a variety of artificial disease resistance genes that are currently being tested against a number of fungal and bacterial pathogens. A major emphasis has been achieving resistance to Aspergillus flavus, the fungus responsible for the biosynthesis of aflatoxin in almonds and walnuts. Another emphasis has been finding a way to reduce the incidence of crown gall infections in tree crops. One approach we are pursuing is to develop a screening technique to evaluate natural resistance to Agrobacterium tumefaciens, the causative agent for the disease in Prunus sp. (Bliss et al., 1999). Recently, we have begun investigating the use of gene silencing to generate artificial resistance to crown gall in walnut rootstocks.

Resistance to nematodes. Nematodes are a significant agricultural pest worldwide causing great economic losses. The situation will worsen in the near future as the use of soil fumigants like methyl bromide are banned worldwide. Crop yield can be dramatically affected by nematode infestation in nonfumigated soil. For example, the yield of cultivated strawberries (Fragaria $\times$ ananassa Duch.) in California is reduced by over $50 \%$ when they are grown in nonfumigated soil (Shaw and Larson, 1999). The presence of nematodes and assorted soil microflora is responsible for much of the yield reductions. Our interest has focused on the parasitic nematode pests that attack walnut and apple. Of interest is to try to express artificial resistance genes that influence the life cycle of the nematode. Candidate genes would include those encoding proteinase inhibitors that affect feeding or lectins that affect both migration and feeding behavior (Jung et al., 1998). Natural nematode resistance genes have been isolated by positional cloning from plants and two of these have been successfully expressed in other commercially produced species (Burrows, 1998). Understanding how these genes work will certainly open the door to engineering resistance to nematodes in other cultivated plants.

\section{IMPROVING PRODUCTIVITY AND QUALITY}

The past several years have witnessed an upsurge in research aimed towards understanding the critical genes involved in productivity, quality, and nutritional content. Molecular approaches have led to the discovery of genes that regulate carbohydrate, lipid, and protein composition (Mazur et al., 1999). Genes that could potentially greatly influence productivity may come from the emerging understanding of the flowering process and corresponding sequences that regulate both timing and positioning of inflorescence development and subsequent fruit set. Among quality traits are genes that regulate phytonutrient accumulation and postharvest shelf-life. Other horticulturally useful genes would include those that regulate tree architecture (e.g., stature and branching), environmental stress resistance (cold and drought), photosynthate production, nitrogen utilization, and mineral nutrition. In short, the growing number of potentially useful traits when combined with the possible target plants represents a huge diversity in the number of possible crop improvement programs. Outlined below are the few on which we currently focus our efforts, along with some relevant background information.

Tree physiology. The patterns of vegetative and reproductive growth in plants are regulated by the partitioning and distribution of assimilated carbon. Therefore, the interaction between source organs involved in partitioning assimilated carbon and various sink organs utilizing this translocated carbon is crucial for biomass production and crop yield. In most plant species, sucrose and starch are the major products of photosynthesis, with sucrose being the major form of carbon translocated to sink tissues where it is utilized in the development of fruit and nuts. A unique aspect of the carbohydrate metabolism of many members of the family Rosaceae resides in their ability to translocate the sugar alcohol sorbitol in addition to sucrose (Fig. 1). The Rosaceae family includes many commercially important tree species, e.g., apple, pear (Pyrus sp.), loquat [Eriobotrya japonica (Thunb.) Lindl.], and Prunus sp. that includes peaches, almonds, cherries, plums, prunes, and nectarines. It has been estimated on a global scale that as much as $30 \%$ of primary production involves sugar alcohols rather than sugars (Bieleski, 1982).

We have been using a transgenic approach to study carbohydrate biology in general and sorbitol metabolism in particular with a number of different plant species. The major questions we are investigating include: 1) What role does the partitioning of sorbitol play in the rate and pattern of vegetative and reproductive growth? and 2) How does sorbitol influence important fruit characteristics such as development, yield, and quality? The relevance of these questions stems from the fact that many roles have been ascribed to the accumulation of sorbitol. One of the more interesting with regard to crop improvement is the possibility of increasing the tolerance to various forms of environmental stress (Loescher and Everard, 1996). Additionally, sorbitol may be involved in the transport of boron, a key micronutrient which may directly influence flowering and fruit set (Brown et al., 1999).

Along these lines, we have been working with a cDNA sequence from apple encoding sorbitol-6-phosphate dehydrogenase (S6PDH), the enzyme found in source tissue that is responsible for the synthesis of sorbitol (Tao et al., 1995). Early results from studying the expression of this cloned sequence in transgenic tobacco (Nicotiana sp.), a species in which sorbitol is not found, demonstrated the central function of this enzyme with regards to sorbitol biosynthesis. Using similar transgenic tobacco plants we later showed that accumulation of sorbitol resulted in an enhanced efficiency of nutrient utilization (Bellaloui et al., 1999; Brown et al., 1999).

To address the above questions of carbohydrate partitioning, we have generated transgenic apple trees expressing S6PDH in either the sense or antisense orientation with the hope of obtaining trees with altered levels of sorbitol accumulation (both higher and lower). A total of 351 trees were introduced to the field in 1997 (Table 1; Dandekar et al., unpublished data). Our primary aim is to evaluate these genetic alterations to determine if specific defects in sorbitol accumulation will help clarify the function(s) of this sugar alcohol in growth, development, and productivity. At the biochemical level in organ tissue, we would like to examine photosynthesis and carbon partitioning by quantifying different carbohydrates and by determining the activity levels of the specific enzymes involved with their metabolism. On a whole-plant basis, we are measuring the rates and patterns of vegetative and reproductive growth, and attempting to correlate these findings with the levels of different carbohydrates and their associated enzymes. Because of the substantial amount of carbohydrate metabolism that exists within plastids, transgenic plants were also created that express S6PDH translationally fused to a chloroplast-targeting transit peptide (Table 1). These plants were also introduced into the field in 1997 (Dandekar et al., unpublished data). Similar biochemical and physiological measurements will be carried out with this second group of transgenic plants.

Finally, in an attempt to begin understanding endogenous genes, we have identified a $3.4 \mathrm{~kb}$ genomic DNA sequence that represents a 


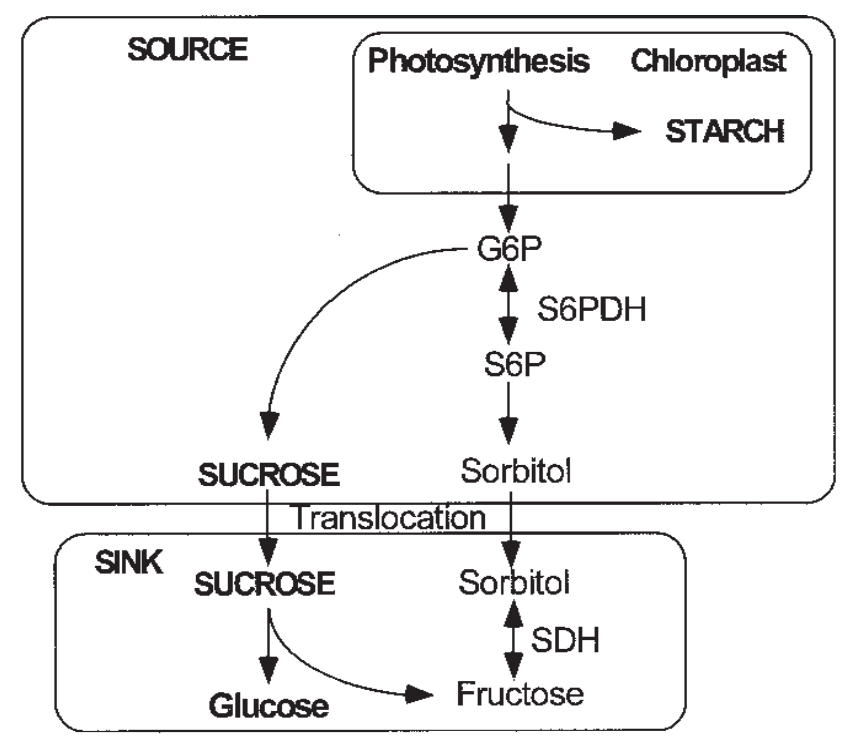

Fig. 1. Major products of photosyntheses in Rosaceous plant speciies.

Table 1. Field planting of transgenic apple with altered sorbitol metabolism. ${ }^{2}$

\begin{tabular}{lllcc}
\hline \hline Cultivar & Vector & \multicolumn{1}{c}{$\begin{array}{c}\text { Transgene } \\
\text { type }\end{array}$} & $\begin{array}{c}\text { Transgenic } \\
\text { lines (no.) }\end{array}$ & $\begin{array}{c}\text { Plants } \\
\text { (no.) }\end{array}$ \\
\hline Greensleeves & pDU93.0330 & Antisense S6PDH & 12 & 50 \\
Ginger Gold & pDU93.0330 & Antisense S6PDH & 15 & 56 \\
Greensleeves & pDU93.0305 & Sense S6PDH & 21 & 81 \\
Ginger Gold & pDU93.0305 & Sense S6PDH & 10 & 40 \\
Greensleeves & pDV95.914.1 & TP-S6PDH & 10 & 36 \\
Ginger Gold & pDV95.914.1 & TPy-S6PDH & 8 & 35 \\
Greensleeves & & Control & --- & 26 \\
Ginger Gold & & Control & -- & 27 \\
& & Total & 76 & 351 \\
\hline
\end{tabular}

${ }^{2}$ Trees were planted in California in 1999.

yS6PDH, sorbitol-6-phosphate dehydrogenase; TP, transit peptide.

full-length clone encoding S6PDH (Bains et al., 1998). In addition, we have cloned $2 \mathrm{~kb}$ of upstream sequences containing the regulatory elements.

Tree architecture. Growth habit of horticultural trees is an important consideration, especially with regard to production costs. The more traditional approach to modification has been through, for example, careful selection of rootstocks, pruning, thinning, and spraying. These efforts may be greatly enhanced through the introduction of transgenes that play a role in growth and/or development. Currently, the best candidate genes for this purpose are plant oncogenes of bacterial origin. The tumor and root forming genes of Agrobacterium modify the balance of the plant growth regulators auxin and cytokinin by stimulating their synthesis or by altering tissue sensitivity to these compounds. The rol genes from Agrobacterium rhizogenes are among the best-characterized oncogenes (reviewed in Costantino et al., 1994). With regard to useful horticultural traits, transgenic plants expressing rol genes have shown reduced internodal distance ( $\mathrm{rol} A$ ), increased adventitious rooting $(\mathrm{rol} B)$, reduced apical dominance and seed set ( $r o l C$ ), and may be useful in limiting juvenility since $r o l D$ has been shown to induce early flower set. Others have reported similar phenotypes but attributed them to a different $\mathrm{rol}$ gene and/or a combination of more than one of the rol coding sequences (see for example Giovannini et al., 1999). It seems likely that plant phenotype as a result of rolgene expression is species or even cultivar specific and therefore must be tested on an individual basis.

We have constructed a variety of vectors for the introduction of rol genes into walnut and citrus. Two of these vectors contained either the rol $A B C$ or rol $B$ coding sequences from Agrobacterium rhizogenes strain A4. Subclones of the TR-DNA of pRiA4 were used. We have obtained transgenic walnut plants expressing rol $A B C$ and these have been introduced into the field. The plants have displayed a remarkable compact phenotype with reduced internode distance. Similar experi- ments are under way with lemon.

Flowering and fruit/nut set. Self-incompatibility (SI) is a widespread inherited reproductive phenomenon in flowering plants that prevents self-fertilization through rejection of self pollen. This trait promotes outcrossing and thus is an important evolutionary mechanism that maintains genetic variability among plant populations. We have been studying this process in almond whereby the mechanism involves termination of germinated pollen tubes within the style of incompatible genotypes. In Prunus species, SI is controlled by a single $S$ locus consisting of several co-dominant $S$-alleles encoding specific ribonucleases (S-RNases) that block self pollen tube growth (Kao and McCubbin, 1996). Almonds grown in California have four predominant $S$-alleles $\left(S^{\mathrm{a}}-S^{\mathrm{d}}\right)$ that can be assembled into seven cross incompatibility groups, depending on the combination of individual $S$-alleles (Kester et al., 1994).

Because self-incompatible plants tend to produce individuals that are heterozygous at the S-locus, choice of the pollen parent becomes critical in an efficient breeding program and depends upon the correct identification of the $S$-alleles. The determination of the $S$-genotype of segregating progeny in a cross is a time-consuming task that involves growing plants to maturity and testing for fruit set with pollen from various known $S$-genotypes. We have developed a PCR-based identification system for individual $S$-alleles that could provide a faster means of identifying not only progeny but also new cultivars and selections (Tamura et al., 2000).

An additional objective of our work in almond is to limit expression of endogenous SRNase genes and in effect reduce the occurrence of self-incompatibility. The strategy we are currently investigating involves the expression of antisense cDNA encoding $S$-alleles. To that end, S-RNases encoded by the $S$-alleles in almond have been isolated and their N-terminal amino acid sequences determined (Tao et al., 1997b). This information was used to isolate and characterize cDNAs corresponding to three of the four $S$-alleles $\left(S^{\mathrm{b}}, S^{\mathrm{c}}\right.$, and $\left.S^{\mathrm{d}}\right)$ of almond (Ushijima et al., 1998). More recently we have been able to recover the cDNA for the remaining $S$-allele, $S^{\text {a }}$ (Tamura et al., 1999). The DNA sequences encoding these SRNases will be used to create antisense expression cassettes and will be inserted into binary vectors for Agrobacterium-mediated transformation. Transformation of almond has been reported (Miguel and Oliveira, 1999), and we are using this method as a basis to develop an optimized transformation protocol for the cultivar Nonpareil, the major commercial variety in California.

Oil/fat composition. Dietary fats/oils contribute significantly to balanced nutrition as they are key in providing energy (calories), fatsoluble vitamins and the essential fatty acids linoleic acid (LEA) and $\alpha$-linolenic acid (ALA), which are required for growth, cell membrane function, development, and disease prevention (Fig. 2). Conversely, fats/oils have also been implicated in a diverse group of health ailments such as obesity, cancer, and heart disease. An emerging body of evidence derived from more recent work suggested that the types of fats/oils consumed and, more specifically, their compositions, were important in promoting good health. Several studies with human subjects have now shown that the consumption of walnuts was associated with distinct health benefits such as improved serum lipid profiles and reduced incidence of disease (Sabate et al., 1993). This was thought to be due to the presence of a greater proportion of $\omega 3\left(\Delta^{15}\right)$ ALA. These observations were corroborated by the finding that the $\omega 3$ fatty acids that include the longer chain fish oils have been shown to not only be important for growth and development, but also for health and disease prevention (Simopoulos, 1991).

Although the benefits from eating walnuts are becoming apparent, there is no information available at the biochemical or molecular levels regarding the genes or mechanisms that regulate oil composition in these seeds. We have initiated a study on the regulation of polyunsaturated fatty acid (PUFA) biosynthesis in walnut kernels. As implied above, walnuts are a rich source of the essential polyunsaturated fatty acids LEA and ALA. The cellular processes leading to their accumulation as stored oils will serve as the early focal points of our investigation. Positioning of the unsaturated double bonds within the molecule, especially near the methyl group, seems to have an important health implication (Fig. 2). As a starting point, we have begun isolating the genes encoding the specific desaturases responsible for 


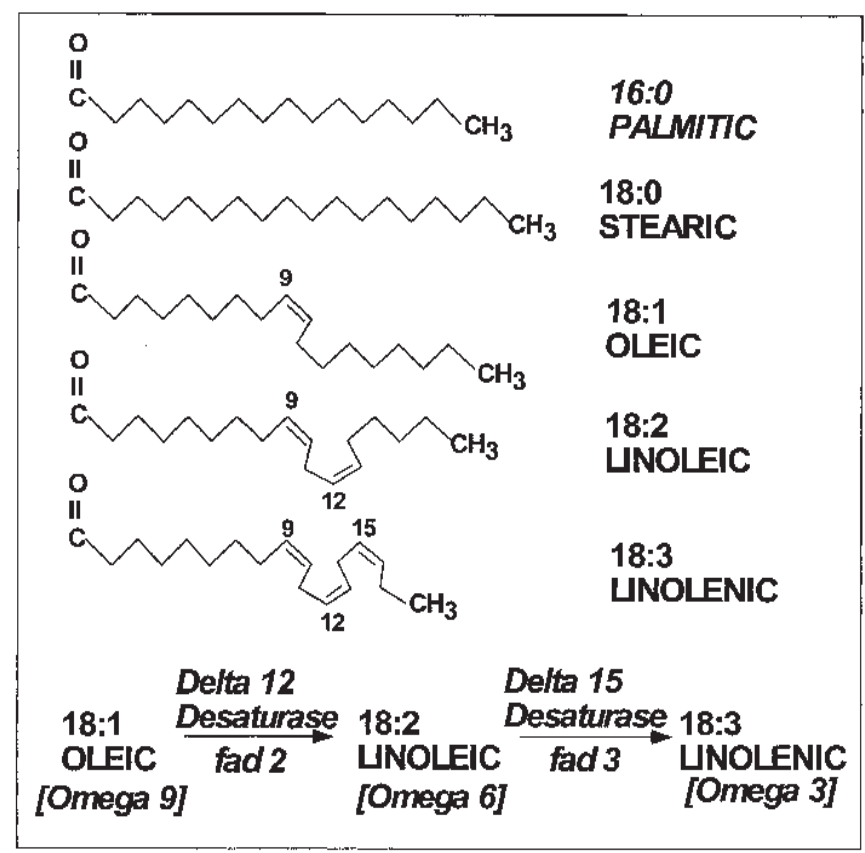

Fig. 2. Structure of fatty acids and pathway for synthesis of polyunsaturated fatty acids.

regulating the synthesis of LEA and ALA in walnuts. We next will initiate experiments aimed at gaining a better understanding of how their expression is controlled in relation to oil composition.

Polyunsaturated oils suffer from a susceptibility to oxidation and associated rancidification. One of the most important quality traits associated with high levels of unsaturated oils is reduced shelf life. Adverse changes caused by oxidation lead to deterioration of flavor, reduction in shelf life, loss of nutritive value, and decreased consumer acceptance. The dilemma with regards to plant improvement efforts is obvious since manipulation of the levels of desaturases (Fig. 2) that could lead to oils less prone to rancidification would more than likely result in oil compositions that offer less health benefits. Consequently, we are considering alternative approaches that involve the synthesis of a lipid soluble antioxidant to reduce the potential for rancidification. Recently, it has been shown that vitamin E ( $\alpha$-tocopherol) content can be elevated in plants through the expression of a single gene $(\gamma-$ tocopherol methyltransferase) that converts the ubiquitous $\gamma$-tocopherol into $\alpha$-tocopherol (Shintani and DellaPenna, 1998). Since $\alpha$ tocopherol is considered a powerful antioxidant, its presence in walnut oil should help mitigate many problems associated with oxidation.

Shelflife/ripening. Most plant improvement approaches in the area of shelf life/ripening must begin with the gaseous plant growth regulator, ethylene. Ethylene affects a diverse set of plant processes including fruit ripening, senescence and response to biotic and abiotic stress (Ecker, 1995; Kieber and Ecker, 1993). In fact, ethylene has been shown to mediate the expression of specific genes that are key to these developmental programs (Ecker, 1995; Fluhr and Mattoo, 1996; Jackson, 1997; Kieber and Ecker, 1993; Theologis, 1994). A key intermediate in the ethylene biosynthetic pathway is 1aminocyclopropane-1-carboxylate (ACC), which is converted from S-adenosyl methionine (SAM) through the action of ACC synthase, the rate limiting step (Adams and Yang, 1979). ACC is then converted to ethylene by the ethylene forming enzyme (EFE) or ACC oxidase as shown in Fig. 3. At a molecular level, cDNAs encoding both ACC synthase (Sato and Theologis, 1989) and EFE/ACC oxidase (Hamilton etal., 1991; Spanu etal., 1991) have been cloned from tomato (Lycopersicon esculentum Mill.). The situation is similar in apple where both ACC synthase (Yip etal., 1991) and EFE/ACC oxidase (Fernandez-Maculet and Yang, 1992) have been characterized and their respective cDNAs identified (Dong etal., 1991, 1992).

The wealth of experimental work and resulting knowledge outlined above has led to some very creative molecular-based approaches to regulating the biosynthesis and action of ethylene. For example, the cDNAs encoding ACC synthase or EFE/ACC oxidase expressed in the antisense orientation caused a decrease in the biosynthesis of ethylene and a delay in ripening (Hamilton etal., 1990; Oeller et al., 1991; Theologis, 1994). Alternative approaches to control the level of ethylene have been through the expression of ACC deaminase from bacteria, an enzyme that metabolizes ACC (Klee etal., 1991) or through the tissue specific expression of the enzymes SAM hydrolase (Good et al., 1994) or SAM decarboxylase (Mehta et al., 1997, 1999) both of which catabolize SAM (see Fig. 3). These latter approaches render the precursors, SAM or ACC, unavailable for ethylene biosynthesis (Fluhr and Mattoo, 1996; Theologis, 1994).

The focus of our effort in the area of ripening/shelf life has been with apple. Much of the classical work on fruit ripening was done with apple. In fact, it was with apple that ethylene was shown to play an important role in the ripening and associated characteristic "climacteric" rise in respiration (Kidd and West, 1925). There was an excellent correlation between the level of ethylene measured in the apple fruit and shelf life. More recently, breeding programs have demonstrated that progeny with inherently low ethylene production can be generated from crosses involving a low producer as one of the parents (Stow et al., 1993). The concentration of ethylene is key to many physiological, genetic, and developmental factors that influence the storability, visual appeal, and eating quality of apples. Traits that contribute to eating quality would include acid content, soluble solids accumulation, flesh firmness, and starch level. Therefore, the control of ethylene biosynthesis in apple could be the key to control not only shelf life but also harvest time or eating quality. We are investigating these possibilities through the expression of antisense mRNA or through the expression of other genes that interfere in the synthesis of ethylene as explained above (Fig. 3). Currently, transgenic apple plants with alterations in ethylene biosynthesis are being field tested (Table 2) and include the following approaches: 1) expression of antisense/sense ACC synthase (Dandekar et al., unpublished data) and 2)expression of antisense/sense EFE (Dandekar et al., unpublished data). It will be some time before the impact of these approaches on apple shelf life and quality can be fully determined.

\section{CONCLUSION}

Plant transformation has provided a way to introduce "any gene from any source," thereby substantially enhancing the range of germplasm available for crop improvement. For over a decade we have been developing Agrobacterium-mediated transformation methods for tree crops and have greatly benefited from the discovery and evaluation of useful traits in other plant species. Initially, the major emphasis was developing resistance to diseases and pests, traits important to growers involved in the production of fruits and nuts. The expression of

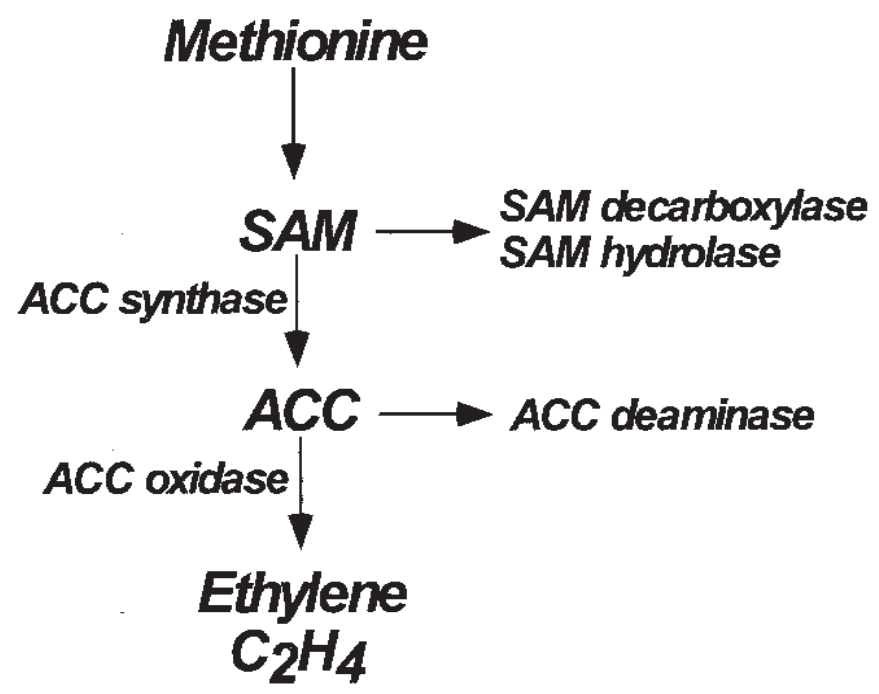

Fig. 3. Metabolic conversion of methionine to ethylene: key steps for the control of ethylene biosynthesis. 
Table 2. Field planting of transgenic apple with altered ethylene metabolism. ${ }^{\mathrm{z}}$

\begin{tabular}{lllcr}
\hline $\begin{array}{l}\text { Cultivar/ } \\
\text { vector }\end{array}$ & Enzyme & Type & $\begin{array}{c}\text { Transgenic } \\
\text { lines (no.) }\end{array}$ & $\begin{array}{r}\text { Plants } \\
\text { (no.) }\end{array}$ \\
\hline Greensleeves & & & & \\
pDU93.0128 & ACC Synthase & Antisense & 7 & 21 \\
pDU93.0114 & ACC Synthase & Sense & 19 & 57 \\
pDU93.0402 & ACC Oxidase & Antisense & 15 & 48 \\
pDU93.0414 & ACC Oxidase & Sense & 11 & 31 \\
Control & & & --- & 8 \\
Royal Gala & & & 5 & 12 \\
pDU93.0128 & ACC Synthase & Antisense & -- & 3 \\
Control & & & 57 & 180 \\
& & Total & & \\
\hline
\end{tabular}

${ }^{2}$ Trees were planted in California in 1999.

${ }^{y}$ ACC, 1-aminocyclopropane-1-carboxylate.

insecticidal proteins from Bacillus thuringiensis to combat specific insect pests serves as a particularly good example of a technology that is working well in the field. By employing this strategy, we have been successful in generating transgenic apple and walnut cultivars with enhanced resistance to codling moth, a key insect pest in these two crops, and in developing transgenic persimmon resistant to other lepidopteran insects. More recently, our emphasis has shifted towards modifying traits that are more consumer oriented such as enhanced quality, nutritional value, and productivity in apple, walnut, citrus, and almond. Specific traits under investigation include sugar and ethylene metabolism to improve shelf life and eating quality in apples, the manipulation of oil/fat composition to improve shelf life and enhance nutritional value in walnut, and self-incompatibility to develop selfcompatible cultivars of almond.

\section{Literature Cited}

Adams, D.O. and S.F. Yang. 1979. Ethylene biosynthesis: identification of 1-aminocyclopropane-1-carboxylic acid as an intermediate in the conversion of methionine to ethylene. Proc. Natl. Acad. Sci. USA 76:170-174.

Bains, H.S., R. Tao, S.L. Uratsu, and A.M. Dandekar. 1998. Genomic nucleotide sequence of a NADP sorbitol-6-phosphate dehydrogenase gene from apple (Accession No. AF057134) (PGR 98-193). Plant Physiol. 118:1533.

Baulcombe, D.C. 1999. Fast forward genetics on virus-induced gene silencing. Curr. Opin. Plant Biol. 2:109-113.

Bellaloui, N., P.H. Brown, and A.M. Dandekar. 1999. Manipulation of in vivo sorbitol production alters boron uptake and transport in tobacco. Plant Physiol. 119:735-742.

Bieleski, R.L. 1982. Sugar alcohols, p. 158-192. In: F.A. Loewus and W. Tanner (eds.). Plant carbohydrates. I. Intracellular carbohydrates. Encyclopedia of Plant Physiology New Series, Vol 13A. Springer-Verlag, Berlin.

Bliss, F.A., A.A. Almedhi, A.M. Dandekar, P.L. Schuerman, and N.I. Bellaloui. 1999. Crown gall resistance in accessions of Prunus species. HortScience 34:326-330

Brown, P.H., N. Bellaloui, H. Hu, and A.M. Dandekar. 1999. Sorbitol synthesis enhances tolerance of B deficiency in transgenic tobacco. Plant Physiol. 119:17-20.

Burrows, P.R. 1998. Plant-derived enzyme inhibitors and lectins for resistance against plant-parasitic nematodes in transgenic plants. Pestic. Sci. 52:176183.

Costantino, P., I. Capone, M. Cardarelli, A. De Paolis, M.L. Mauro, and M. Trovato. 1994. Bacterial plant oncogenes: the rol genes' saga. Genetica 94:203-211

Dandekar, A.M., G.H. McGranahan, S.L. Uratsu, C. Leslie, P.V. Vail, S.J. Tebbets, D.Hoffman, J. Driver, P. Viss, and D.J. James. 1992. Engineering for apple and walnut resistance to codling moth. Proc. of the Brit. Council for Crop Prot. Conf.-Pests and Diseases, Vol. 2, p. 741-747. Brit. Council for Crop Protection, Cambridge, U.K.

Dandekar, A.M., G.H. McGranahan, P.V. Vail, S.L. Uratsu, C.A. Leslie, and J.S. Tebbets. 1998. High level of expression of full length cryIA(c) gene from Bacillus thuringiensis in transgenic somatic walnut embryos. Plant Sci. 131:181-193.

Dandekar, A.M., G.H. McGranahan, P.V. Vail, S.L. Uratsu, C.A. Leslie, J.S. Tebbets, and D.J. Hoffman. 1994. Low levels of expression of cryIA(c) sequences of Bacillus thuringiensis in transgenic walnut. Plant Sci. 96:151162.

Dong, J-G., W.T. Kim, W.K .Yip, G.A. Thompson, L. Li, A.B. Bennett, and SF. Yang. 1991.Cloning of a cDNA encoding 1-aminocyclopropane-1carboxylate synthase and expression of its mRNA in ripening apple fruit. Planta. 185:38-45.
Dong, J-G., D.B. Olsen, A. Silverstone, and S-F. Yang. 1992. Sequence of a cDNA encoding for a 1-aminocyclopropane-1-carboxylate oxidase homolog from apple fruit. Plant Physiol. 98:1530-1531.

Ecker, J.R. 1995. The ethylene signal transduction pathway in plants. Science 268:667-675.

Escobar, M. and A.M. Dandekar. 2000. Development of insect resistance in fruit and nut tree crops, p. 395-417. In: S.M. Jain and S.C. Minocha (eds.). Molecular biology of woody plants. vol. 2.Kluwer, Dordrecht, Netherlands.

Fernandez-Maculet, J.C., and S.F. Yang. 1992. Extraction and partial characterization of the ethylene-forming enzyme from apple fruit. Plant Physiol. 99:751-754

Fluhr, R and A.K. Mattoo. 1996. Ethylene: Biosynthesis and perception. Critical Rev. Plant Sci. 15:479-523.

Giovannini, A., M. Zottini, G. Marreale, A. Spena, and A. Allavena. 1999. Ornamental traits modification by rol genes in Osteospermum ecklonis transformed with Agrobacterium tumefaciens. In Vitro Cell. Dev. Biol. Plant 35:70-75.

Good, X., J.A. Kellogg, W. Wagoner, D. Langhoff, W. Matsumura, R.K. Bestwick. 1994. Reduced ethylene synthesis by transgenic tomatoes expressing S-adenosylmethionine hydrolase. Plant Mol. Biol. 26:781-790.

Hamilton, A.J., M. Bouzayen, and D. Grierson. 1991. Identification of a tomato gene for the ethylene-forming enzyme by expression in yeast. Proc. Natl. Acad. Sci. USA 88:7434-7437.

Hamilton, A.J., G.W. Lycett, and D. Grierson. 1990. Antisense gene that inhibits synthesis of the hormone ethylene in transgenic plants. Nature 346:284-287.

Jackson, M. 1997. Hormones from roots as signals for the shoots of stressed plants. Trends Plant Sci. 2:22-28.

Jung, C., D. Cai, and M. Kleine. 1998. Engineering nematode resistance in crop species. TIBTEC 3:266-271.

Kao, T.H. and A.G. McCubbin. 1996. How flowering plants discriminate between self and non-self pollen to prevent inbreeding. Proc. Natl. Acad. Sci. USA 93:12059-12065.

Kester, D.E., T.M. Gradziel, and W.C. Micke. 1994. Identifying pollen incompatibility group in California almond cultivars. J. Amer. Soc. Hort. Sci. 119:106-109.

Kidd, F. and West, C. 1925. The course of respiratory activity throughout the life of an apple. Grt. Brit. Dept. Sci. Ind. Res., Food Invest. Bd. Rpt. for 1924:27-33.

Kieber, J.J. and J.R. Ecker. 1993. Ethylene gas: It's not just for ripening any more. Trends Genetics 9:356-362.

Klee, H.J., M.B. Hayford, K.A. Kretzmer, G.F. Barry, and G.M. Kishore. 1991. Control of ethylene synthesis by expression of a bacterial enzyme in transgenic tomato plants. Plant Cell 3:1187-1193.

Lamb, C.J., M.A. Lawton, M. Dron, and R.A. Dixon. 1989. Signals and transduction mechanisms for activation of plant defenses against microbial attack. Cell 56:215-224.

Loescher, W.H. and J.D. Everard. 1996. Sugar alcohol metabolism in sink and sources, p.185-207. In:E.Zamski and A.A. Schaffer(eds.). Photoassimilate distribution in plants and crops: Source-sink relationships. Marcel Dekker, New York.

Mazur, B., E. Krebbers, and S. Tingey. 1999. Gene discovery and product development for grain quality traits. Science 285:372-375.

Miguel, C.M. and M.M. Oliveira. 1999. Transgenic almond (Prunus dulcis Mill.) plants obtained by Agrobacterium-mediated transformation of leaf explants. Plant Cell Rpt. 18:387-393.

Mehta, R., A. Handa, and A.K. Mattoo. 1997. Interactions of ethylene and polyamines in regulating fruit ripening, p. 321-326. In: A.K. Kanellis, C. Chang, H. Kende, and D.Grierson (eds.). Biology and biotechnology of the plant hormone ethylene. Kluwer Acad. Publ., Boston.

Mehta, R., A. Handa, and A.K. Mattoo. 1999. Ethylene, polyamines and fruit ripening, p.591-595. In: A. Altman, M. Ziv, and S. Izhar (eds.). Plant biotechnology and in vitro biology in the 21st century. Kluwer Acad. Publ., Boston.

Oeller, P.W., L. Min-Wong, L.P. Taylor, D.A. Pike, and A. Theologis. 1991 Reversible inhibition of tomato fruit senescence by antisense RNA. Science 254:437-439.

Perlak, F.J., R.L. Fuchs, D.A. Dean, S.L. McPherson, and D.A. Fischhoff. 1991. Modification of the coding sequence enhances plant expression of insect control protein genes. Proc. Natl. Acad. Sci. USA 88:3324-3328.

Ryals, J. and E. Ward. 1994. Systemic acquired resistance. Plant Physiol. 104:1109-1112.

Sabate, J., G.E. Fraser, K. Burke, S.F. Knutsen, H. Bennett, and K.D. Lindsted. 1993. Effects of walnuts on serum lipid levels and blood pressure in normal men. New Eng. J. Med. 328:603-607.

Sato, T. and A. Theologis. 1989. Cloning the mRNA encoding 1aminocyclopropane-1-carboxylate synthase, the key enzyme for ethylene synthesis in plants. Proc. Natl. Acad. Sci. USA 86:6621-6625. 


\section{Colloquium}

Schnepf, E., N. Crickmore, J. Van Rie, D. Lerecus, J. Baum, J. Feitelson, D.R. Zeigler, and D.H. Dean. 1998.Bacillus thuringiensis and its pesticide crystal proteins. Microbiol. Mol. Biol. Rev. 62:775-806.

Shaw, D.V. and K.D. Larson. 1999. A meta-analysis of strawberry yield response to preplant soil fumigation with combinations methyl bromidechloropicrin and four alternative systems. HortScience 34:839-845.

Shintani, D. and D. DellaPenna. 1998. Elevating the vitE content of plants through metabolic engineering. Science 282:2098-2100.

Simopoulos, A.P. 1991. Omega-3 fatty acids in health and disease and in growth and development. Amer. J. Clin. Nutr. 54:438-463.

Spanu, P., D. Reinhardt, and T. Boller. 1991. Analysis and cloning of the ethylene-forming enzyme from tomato by functional expression of its mRNA in Xenopus laevis oocytes. EMBO J. 10:2007-2013.

Stow, J.F. Alston, S. Hatfield, and P. Genge. 1993. New selections with inherently low ethylene production. Acta Hort. 326:85-92.

Tamura, M.K., T.M. Gradziel, and A.M. Dandekar. 1999. Cloning of genomic DNA sequences encoding almond (Prunus dulcis) S-RNase genes (Accession No. AF148465, AF148466, AF148467, AF148468)(PGR-117). Plant Physiol. 124(4):1206.

Tamura, M.K., K. Ushijima, H. Sassa, H. Hirano, R. Tao, T.M. Gradziel, and A.M. Dandekar. 2000. Identification of self-incompatibility genotypes of almond by allele specific PCR analysis. Theor. Appl. Genet. 101:344-349.

Tao, R., A.M. Dandekar, S.L. Uratsu, P.V. Vail, and J.S. Tebbets. 1997a.
Engineering genetic resistance against insects in Japanese persimmon using the cryIA(c) gene of Bacillus thuringiensis. J. Amer. Soc. Hort. Sci. 122(6):764-771.

Tao, R., S.L. Uratsu, and A.M. Dandekar. 1995. Sorbitol synthesis in transgenic tobacco with apple cDNA encoding NADP-dependent sorbitol-6-phosphate dehydrogenase. Plant Cell Physiol. 36:525-532.

Tao, R., H. Yamane, H. Sassa, T.M. Gradziel, A.M. Dandekar, and A. Sugiura 1997b. Identification of stylar RNases associated with gametophytic selfincompatibility of almond (Prunus dulcis). Plant Cell Physiol. 38(3):304311.

Theologis, S.T. 1994. Control of ripening. Curr. Opinion Biotechnol. 5:152157.

Ushijima, K., H. Sassa, R. Tao, H. Yamane, A.M. Dandekar, T.M. Gradziel, and H. Hirano. 1998. Cloning and characterization of cDNAs encoding the S-RNases in almond (Prunus dulcis): Primary structural features and sequence diversity of Rosaceous S-RNases. Mol. Gen. Genet. 260:261268

Vail, P.V., J.S. Tebbets, D.F. Hoffmann, and A.M. Dandekar. 1991. Response of production and postharvest walnut pests to Bacillus thuringiensis insecticidal crystal protein fragments. Biol. Control 1:329-333.

Yip, W-K., J-G. Dong, and S.F. Yang. 1991. Purification and characterization of 1-aminocyclopropane-1-carboxylate synthase from apple fruits. Plant Physiol. 95:251-257. 